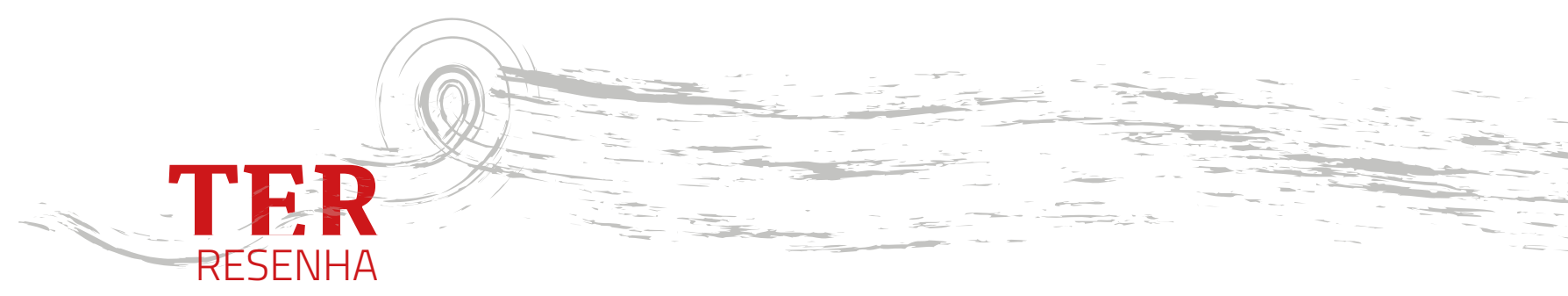

Universidade Estadual de ALEXSÂNDER NAKAÓKA ELIAS ${ }^{1}$

Campinas, Campinas, Brasil.

\title{
FOTOGRAFIA E IMPÉRIO: PAISAGENS PARA UM BRASIL MODERNO
}

Natalia Brizuela. 2012. Fotografia e Império: paisagens para um Brasil moderno. São Paulo, Companhia das Letras, 248p.
Na obra intitulada Fotografia e Império: paisagens para um Brasil moderno, Natalia Brizuela (2012) apresenta ao leitor um panorama do Brasil oitocentista a partir de fotografias, explicitando que esses registros estiveram intensamente presentes na construção do imaginário nacional. Assim, indica uma importante relação entre as fotografias desse período e a configuração do território brasileiro durante o reinado de D. Pedro II, passando pela coinvenção da fotografia por Hercule Florence, pela abolição da escravatura e pela formação da Nova República.

A autora reflete sobre as relações entre o campo fotográfico e o contexto sócio-histórico do qual ele emerge, principalmente por meio do retrato (cujas pessoas são o tema central) e da paisagem (cenários nos quais as pessoas também podem estar inseridas), dois importantes gêneros que marcaram o início da prática fotográfica. Para tanto, Brizuela destaca duas figuras como tipos potenciais de fotógrafos no Brasil Imperial. o primeiro é o viajante-fotógrafo, personagem ligado às paisagens e responsável por retratar as principais cidades brasileiras (Rio de Janeiro, Recife e Salvador), oferecendo um atlas do país através da imagem fotográfica. Já o amante-fotógrafo consiste em um retratista capaz presentificar aqueles que estão ausentes por meio da memória visual, uma atuação ligada ao mesmo tempo à ordem do afetivo, do invisível e do imaginário: "Um atlas do espaço e um atlas da emoção, agregados por uma 'arte científica”' (Ibid., 39).

1. Bolsista da Fundação deAmparo à Pesquisa do Estado de São Paulo(Fapesp). 
Assim, Brizuela compõe seu livro com um prólogo e quatro ensaios de imagens que dialogam com o texto. Nesse sentido, embora as fotografias apareçam ao longo da obra em tamanho reduzido e acompanhadas de legendas explicativas, elas são revistas em boa resolução no belo encarte localizado no final da obra, o que é fundamental para entender as reflexões da autora, cujo intento é compreender as fotografias como produtos culturais que constituem "mapas nada objetivos e muito mágicos"2 do Brasil (Ibid., 15).

No primeiro ensaio Brizuela examina os modos como o Segundo Império (1840-1889) utilizou a fotografia para implantar o projeto de construir uma imaginação geográfica da nova colônia e desenvolver um sentimento nacionalista. Nesse contexto, a fotografia será associada à arte da cartografia, ao projeto oficial do romantismo e ao trabalho do Instituto Histórico e Geográfico Brasileiro (IHGB), mostrando uma relação entre o desenvolvimento cultural do Segundo Império, sob a regência de D. Pedro II, e a chegada e consolidação da fotografia no Brasil.

As imagens do primeiro capítulo exibem ao leitor as chamadas vistas, nome dado às fotografias de paisagens no século XIX e que mostravam 0 Brasil com uma natureza aparentemente inexplorada pelo homem, que precisava tornar-se pública. Porém, Brizuela chama a atenção para o fato de que essas fotografias nunca são o objeto em si, ou seja, "não existe paisagem antes que um sujeito humano a configure como tal" (Ibid., 26). Para a autora, as vistas se constituem como lugares construídos pelos fotógrafos para serem vistos, seja pela escolha de um enquadramento ou pela presença de uma figura humana, que aparece em meio ao cenário selvagem. Tais aparições nos fazem, nesse sentido, desconfiar das imagens, "porque agora sabemos que a fotografia não é só a natureza imprimindo a si mesma, mas o produto de um observador subjetivo" (Ibid., 30).

Após oferecer ao leitor essas vistas, a autora inicia o segundo ensaio estabelecendo um contraponto ao primeiro capítulo do livro, que é composto pela história oficial da chegada da fotografia ao Brasil, importada da Europa com o auxílio de D. Pedro II ${ }^{3}$. Agora o eixo central não são mais as imagens produzidas nos núcleos da corte colonial, mas os experimentos fotográficos de Hercule Florence, francês radicado no Brasil que "inventou", na vila de são Carlos (atual cidade de Campinas, São Paulo),

2. Mesmo que, paradoxalmente, a ontologia fotográfica esteja ligada a um ideal de objetividade, isto é, consista em uma técnica elaborada graças aos avanços da racionalização e da ciência. Nesse sentido, a fotografia estaria a meio caminho da arte e da ciência, como se mostra no livro Entre arte e ciência: a fotografia na antropologia, organizado por Sylvia Caiuby Novaes (2015).

3. D. Pedro II, grande admirador e colecionador de fotografias, organizou um conjunto de 25 mil imagens de todos os tipos: retratos, paisagens, vistas urbanas, astronomia, biologia, zoologia etc. 
um método de impressão solar com o intuito de estabelecer uma técnica de reprodução comercial. Brizuela nos mostra que os primeiros esforços de Florence resultaram, no ano de 1833, em uma cópia de rótulos comerciais de uma farmácia, que o próprio autor denominou de photographie, apontando para o uso da fotografia como um bem de consumo ${ }^{4}$, uma mercadoria com o intuito de reprodutibilidade.

Essa diferença de utilização é nítida com as duas primeiras fotografias apresentadas no segundo capítulo e que foram expostas na mesma página (Ibid., 63). A primeira é denominada "Paço da Cidade" (Rio de Janeiro, 1840), um daguerreótipo feito pelo padre Louis Compte; considerada a primeira imagem produzida a partir dessa técnica no Brasil, mostra uma cena do palácio que abrigou D. Pedro I e D. Pedro II, um símbolo urbano do Império. Já a segunda é uma imagem de Florence (datada de 1839) que se assemelha mais a um desenho ou a uma estampa, sendo que a impressão de realidade direta está ausente. Porém, embora ressalte essas distinções, Brizuela afirma que ambas são fotografias e tentativas de reencantar o mundo, seja por construir um imaginário urbano imperial ou por revelar uma história que aconteceu à margem das cortes, distante dos centros de poder do país ${ }^{5}$.

Assim, Brizuela narra o contexto de produção das imagens de Florence, que veio para o Brasil no intuito de trabalhar como pintor naturalista na expedição científica do barão Georg Heinrich von Langsdorff (1825-1829), na qual foi contratado para desenhar e catalogar os cenários e os novos espécimes de animais e plantas encontrados. Tendo intenção de reproduzir um manuscrito que escrevera durante sua participação na expedição, Florence se deparou com dificuldades técnicas, pois a única gráfica existente na região de São Paulo se recusou a publicar um trabalho desse tipo, fato que o estimulou a desenvolver um novo método de impressão mais democrático. "Photographie: um modo de imprimir imagens que surgiu do desencantamento com a observação da natureza” (Ibid., 75). Portanto, a photographie de Florence consistiu em um retorno às técnicas racionais, pois era fruto de um processo químico/físico; derivou também de um anseio por autenticidade e criação, revivendo as distinções entre original/cópia e natureza/cultura e antecipando discussões clássicas tanto para a fotografia quanto para a antropologia.

\footnotetext{
4. Boris Kossoy (2006), no livro Hercule Florence: a descoberta isolada da fotografia no Brasil, reivindica a importância dos experimentos que Florence realizou com nitrato de prata, inclusive cunhando e utilizando o termo photographie pela primeira vez, em 1833.

5. Além disso, a autora destaca que a photographie de Florence apresentava semelhanças formais (como os enquadramentos que ressaltam a intervenção humana a partir de um ponto de vista) com as primeiras imagens fotográficas produzidas por Niépce, Daguerre e Talbot, considerados os pioneiros da prática na Europa.
} 
Já no terceiro ensaio, Brizuela retorna às imagens produzidas no espaço da corte colonial. Agora, a autora mostra ao leitor que os negros escravizados eram retratados nas fotografias do Império como "tipos" raciais. Dessa maneira, afirma que tais imagens não podem ser visualizadas "apenas" como retratos convencionais, mas como signos da escravidão e como forma de compreender a organização do espaço brasileiro da época. Brizuela parte do estudo das chamadas cartes de visite ou timbres-poste (selos postais), produzidas na década de 1860, as quais mostravam escravos posando em estúdios da então capital brasileira, o Rio de Janeiro, durante atividades cotidianas. Tais fotografias eram vendidas como suvenires das terras tropicais, uma espécie de lembrança para os viajantes europeus que mostravam os "tipos" de escravos do Brasil. Essa forma de apropriação coincide com os usos da fotografia na Europa, inclusive com as práticas antropométricas vigentes no século XIX, que davam ênfase a uma catalogação dos "espécimes" humanos, uma cartografia cultural indicativa da superioridade do homem branco.

Brizuela destaca, assim, a existência do que chamou de "triunvirato" das fotografias de retrato, constituído por retratista, modelo e observador, uma relação que expõe importantes e profundas revelações. Seja na mulher do retrato de Stahl (Ibid., 109), que olha para a câmera mostrando ao fotógrafo as marcas em sua face e os dentes frontais, indícios da condição de escrava; seja nas imagens de Christiano Júnior (Ibid., 136) que retratavam cenas de trabalho dos escravizados vestindo roupas típicas da representação dos negros na cultura visual brasileira da época, o que se pode conhecer por essas imagens é parte daquilo que está registrado na fotografia, mas leva para outro lugar, intrinsecamente relacionado ao contexto sociocultural brasileiro.

Dessa maneira, a autora persegue indícios, intimidades e segredos das imagens fotográficas. E nos provoca a fazer o mesmo, ao dizer que não sabemos, por exemplo, os nomes dos personagens, suas idades ou países de origem. A partir desse minucioso trabalho, o leitor é convidado a mergulhar nas fotos e ver além da superfície do papel, ao considerar o propósito para o qual a fotografia foi realizada e, também, sua forma de circulação. Nesse sentido, Brizuela enfatiza que, se tomarmos tais imagens como "simples" retratos, elas não passarão de "naturezas-mortas", com uma capacidade de alienação que oferece não a captura da realidade e de um fragmento da vida, mas um objeto petrificado (Ibid., 123).

Ao pensar nas relações de produção e circulação das cartes-de-visite, Brizuela expõe um momento crucial da história cultural brasileira, que consiste no início do período abolicionista ${ }^{6}$. Essas fotografias apresen-

6. A Lei Eusébio de Queirós, em 1850, proibiu o tráfico negreiro. Em 1871, foi promulgada a Lei do Ventre Livre, que considerava livre todos os filhos de mulheres escravizadas nascidos a 
tam o trabalho dos negros deslocados de uma paisagem e do seu contexto, um apagamento da imagem desses sujeitos que está associado diretamente ao fim do tráfico negreiro e da monarquia no Brasil. É a partir dessa análise que a autora faz a ligação com o último ensaio do livro, no qual exibe imagens do fotógrafo Flávio de Barros, produzidas no contexto da Guerra de Canudos, em 1897.

Diferentemente das imagens mostradas no capítulo anterior (produzidas no ambiente higienizado dos estúdios fotográficos da corte) e das fotografias expostas no primeiro capítulo (produzidas para ressaltar o ideal monárquico de natureza exótica dos trópicos), as imagens de Barros exibem cenários devastados e distantes da fantasia da representação fotográfica do Brasil colonial. Elas são exibidas para responder a um importante questionamento: "para onde foi, então, o Brasil tropical?" (Ibid., 151).

De fato, essas imagens de ruínas compõem para Brizuela um novo tipo de "natureza-morta", produzidas com o intuito de mostrar as provas da batalha incansável entre o homem moderno e o ambiente hostil do sertão nordestino. Se por um lado a tecnologia não permitia que as fotografias fossem tomadas durante o combate, em "tempo real", pois as longas exposições impossibilitavam captar os movimentos no campo de batalha, por outro, Barros fotografava apenas as cenas encomendadas pelos comandantes das tropas, pois foi contratado pelos militares da Nova República para registrar a vitória contra Antonio Conselheiro, líder messiânico de Canudos e visto como um rebelde monarquista.

Ao falar sobre as imagens feitas por Flávio de Barros, Brizuela também introduz outro importante personagem da Guerra de Canudos: Euclides da Cunha, incumbido de ir até a região do conflito armado para fotografar e para produzir relatos escritos; inicialmente um fervoroso apoiador do regime republicano, o que pode ser percebido nas duas primeiras partes de sua obra-prima literária, Os sertões (1902/2002) 7 . Porém, a autora chama a atenção para o fato de que, após percorrer mais de seiscentas páginas do livro, no momento de descrever o clímax da guerra, o jornalista interrompe a narrativa e se volta à descrição prolongada de uma fotografia, como se desconfiasse da sua suposta objetividade e, consequentemente, do ideal republicano.

partir daquele momento. Em 1888, a princesa Isabel, regente do Império Brasileiro, assinou a Lei Áurea que aboliu a escravidão. No dia 15 de novembro de 1889 foi oficialmente proclamada a República do Brasil.

7. O livro Os sertões: campanha de Canudos (1902/2002) se divide em três partes: "A terra", "o homem" e "a luta". 
Assim, Euclides descreve o momento em que o exército, por meio do fotógrafo oficial Flávio de Barros, retrata os restos mortais de Antônio Conselheiro, sendo tal imagem o símbolo de que o país extinguia definitivamente o ideal monárquico, transposto para a figura do líder messiânico (Ibid., 181). A fotografia transformava, mais uma vez, o corpo humano em suvenir, como acontecia com os escravizados brasileiros que serviam de modelo para as cartes-de-visite. À primeira vista, tal imagem retrata um homem em sono tranquilo, com os braços cruzados sobre o peito, a cabeça virada e os olhos pouco visíveis entre o cabelo e a barba. Mas Brizuela chama a atenção para os detalhes da imagem ao dizer que o corpo não está à sombra de uma árvore e que o terreno ao redor mostra que não se trata de uma pessoa em repouso, mas de um cadáver no solo árido do sertão.

Sobre o mesmo ponto, Brizuela ainda constrói uma importante relação entre a imagem de Antônio Conselheiro e os retratos de D. Pedro II, que sempre é mostrado "como um homem velho, mesmo quando ainda tinha vinte e poucos anos" (Ibid., 183), com uma grande barba e um físico imponente. Dessa forma, a autora interpreta a imagem de Conselheiro: um homem também com mais idade e com uma grande barba, mas cujo corpo está frágil e sem vida, como a figura simetricamente invertida do imperador, o que representaria simbolicamente "a morte final da soberania do monarca" (Ibid., 183).

Assim, ao relacionar as imagens da Guerra de Canudos com as do Segundo Império, Brizuela ressalta novamente a polissemia da fotografia, capaz de construir imaginários bem distintos. Seja na construção visual de um país selvagem, com uma natureza inóspita; na visualização de um sertão árido onde o progresso precisa adentrar e controlar; nas photographies ao mesmo tempo técnicas e mágicas de Florence, que narram uma história às margens do Império; ou como meio para estabelecer 0 simbolismo da escravidão no Brasil, o livro de Brizuela reúne e faz explodir sensações contraditórias: objetividade e subjetividade, presença e representação, o aparecimento e o desaparecimento, uma forma de, ao mesmo tempo, desencantar e reencantar a natureza e o mundo.

\section{REFERÊNCIAS BIBLIOGRÁFICAS}

Brizuela, Natalia. 2012. Fotografia e império: paisagens para um Brasil moderno. São Paulo: Companhia das Letras.

Caiuby Novaes, Sylvia, org. 2015. Entre arte e ciência: a fotografia na antropologia. São Paulo: Edusp.

Cunha, Euclides. 1902/2002. Os sertões: campanha de Canudos. São Paulo: Ateliê. 
Kossoy, Boris. 2006. Hercule Florence: a descoberta isolada da fotografia no Brasil, $3^{\text {a }}$ ed. São Paulo: Edusp.

\section{ALEXSÂNDER NAKAÓKA ELIAS}

Jornalista e doutorando em Antropologia Social na Unicamp (bolsa FAPESP), estudando temas relacionados com imagem, antropologia da imagem, religião, simbolismo, rituais, narrativas verbo-visuais e cultura oriental. Mestre pelo Programa de Pós-Graduação em Multimeios (Fotografia e Cinema) do Instituto de Artes da Unicamp, com graduação em Comunicação Social pela Universidade Federal do Espírito Santo.

recebido Tem interesse pelo estudo das linguagens imagéticas, em especial pela 08.07.2017 fotografia, pelo cinema e pelo desenho. É pesquisador do Laboratório Anaprovado tropológico de Grafia e Imagem (LA'GRIMA) e do Grupo de Estudos Visuais 17.10.2017 e Urbanos da Unifesp (Visurb). 